[Agr. Biol. Chem., Vol. 28, No. 7, p. 436 442, 1964]

\title{
Isolation and Identification of Phenolic Acids in Rice Vinegar
}

\author{
By Kazuyuki Maekawa and Masanobu Kodama \\ Department of Agricultural Chemistry, Faculty of Agriculture, \\ Ehime University, Matsuyama, Japan
}

Received December 27, 1963

\begin{abstract}
The fractions obtained from the ether soluble part of rice vinegar were separated by means of cellulose column and of Amberlite XE-64 ion exchange resin. The following compounds were identified: $p$-hydroxyphenylethanol, $p$-hydroxyphenylacetic acid, $p$-hydroxyphenyllactic acid, $p$ hydroxybenzoic acid and phenyllactic acid.
\end{abstract}

There has been no report published on the existence of phenolic acids in rice vinegar. However, the tyrosol found in sake $\mathrm{s}^{1,9)}$ and other compounds can be considered to arise from the carbohydrates and proteins of the raw materials by the action of bacteria or yeasts during the fermentation ${ }^{2 \sim 7,9 \sim 11}$.

The experiment presented here was carried out with a sample of rice vinegar whose raw materials and manufacturing processes were known and from which all kinds of antiseptics were excluded at all manufacturing stages. After some fractions of phenolic acids were separated by column chromatography, five compounds were identified.

\section{EXPERIMENTAL}

\section{Preparation of Samples.}

Rice vinegar used was a commercial product named, "Fundokin-Komesu", manufactured by Kotegawa Soy Sauce Manufacturing Co., Oita, Japan, under the

1) S. Kayahara, and T. Uemura, Nippon Nogei Kagaku Kaishi, 31, $\$ 8(1957)$.

2) X. Chia, This Jonrnal, 22, 136 (1958).

3) F. Kiermeier and R. Jarczynksi, Z. Lebensm. Untersuch. u. Forsch., 113, $370(1960)$.

4) R. Sievens, Nature, 191, 913 (1961)

5) K. Kato, Chiba Igatukai Zasshi, 22, 416 (1956).

6) K. Hirai, T. Himeno and T. Kuroda, Bull. Pharm. Res. Insl, 5, 1 (1953).

7) T. Tanaka, ibid., 18, I (1958).

8) Y. Obta, Eiyo to Shokuryo, 6, 52 (1957).

9) K. Aso and T. Nakayama, Hakko Kogaku Zasshi, 32, 52 (1954)

10) K. Aso, and T. Nakayama, ibid., 31, 43 (19.53)

11) T. Okada, Med. J. Osaka Univ., 6, 697 (1955). supervision of one of the authors (Kodama) in Oct. 1962.

Twenty liters of the rice vinegar was concentrated under reduced pressure, ca. $30 \sim 40 \mathrm{mmHg}$, until about $500 \mathrm{ml}$ of syrup was obtained. The concentrate was extracted with ether. The ether solution was shaken with $1 \mathrm{~N}$ sodium bicarbonate solution until carbon dioxide evolution ceased. The sodium bicarbonate solution of about $300 \mathrm{ml}$ was washed three times with $100 \mathrm{ml}$ ether, and then acidified with $5 \mathrm{~N}$ sulfuric acid. The acidified solution was reextracted with ether continuously. After the ether solution was dried with anhydrous sodium sulfate for a few days as usual, the ether was distilled, and moreover the residual acetic acid in the solution was evaporated as much as possible on a water bath. The residue was dissolved in dilute aqueous ammonia. After removed the excess ammonia, the resulting solution was used as a sample. The yield was about $2 \mathrm{~g}$.

\section{Methods.}

(a) Sample Fractionation on Cellulose Columns.

Column: cellulose powder $(90 \%$ of $100 \sim 200$ mesh powder and $10 \%$ of 300 mesh powder) was packed into $2 \times 50 \mathrm{~cm}$ column.

Developing solvent: $n$-butanol saturated with $1.5 \mathrm{~N}$ aqueous ammonia (butanol was shaken with $1.5 \mathrm{~N}$ ammonia for 20 minutes at room temperature and allowed to stand still overnight) .

(b) Column Chromatography by Ion Exchange Resin. Resin: Amberlite XE-64, 100 200 mesh, $\mathrm{H}^{+}$form.

12) T. Nakaoki, Yakugaku Zasshi, 75, 171 (1955).

13) M.T.J. Abbot, J.F. Grove and R. MeClosky, J. Chem. Soc., $1958,1699$. 
Column: $0.65 \times 95 \mathrm{~cm}$.

Developing solvent: methylethylketone : acetone : $0.2 \mathrm{~N} \mathrm{HCl}=2: 1: 6$. The resin was prepared in accordance to the procedure followed by Moore and Stein ${ }^{14}$. The flow rate was $2 \frac{1}{2} \mathrm{drops} / \mathrm{min}$. and every gram was collected by a fraction collector.

\section{RESULTS}

About $0.5 \mathrm{~g}$ of sample was applied on the top of cellulose column (a) and $2 \mathrm{ml}$ fractions collected. From each fraction $0.5 \mathrm{ml}$ was withdrawn and after $0.5 \mathrm{ml}$ of water was added, the solvent was evaporated in a water bath to remove butanol. The dried eluates were dissolved in water and checked by Pauly's diazo reaction. The results are shown in Fig. 1.

\section{(1) Purification and Identification of Fraction 1 (Fig} 1).

The effuent corresponding to fraction 1 was collected and evaporated to dryness at $80^{\circ} \mathrm{C}$. Small amounts of crystals were obtained. The crystals were dissolved in ether and reprecipitated with petroleum ether, in order to obtain slightly yellowish plate-like crystals, m.p. $98^{\circ} \mathrm{C}$. Physical properties of this compound, the $R_{F}$ value of paper chro- matography, purple color reaction with diazo* tized $p$-nitroaniline, blue coloration by ferric sulfate and potassium ferricyanide, ultraviolet spectrum, and the odor indicated that the compound was p-hydroxyphenylethanol (tyrosol). Finally it was identified by means of the mixed melting point determination with an authentic sample of tyrosol.

(2) Purification and Identification of Fraction 3 (Fig. 1).

The eluate of fraction 3 (Fig. 1) was collected and rechromatographed with ion exchange column (b). Each fraction was evaporated to dryness in water bath to remove solvent, and then dissolved in $4 \mathrm{ml}$ of water. The optical density at $260 \mathrm{~m} \mu$ was measured with the results shown in Fig. 2 (The maximum absorption may differ each fraction, but the measurement was carried out at $260 \mathrm{~m} \mu$ for the sake of convenience).

(2-1) Identification of fraction 3-(4), (peak 4 in Fig. 2).

Evaporation of the solvent of this fraction on a water bath, yielded a slightly yellowish oily material. After standing for a few days at room temperature the residue crystallized.

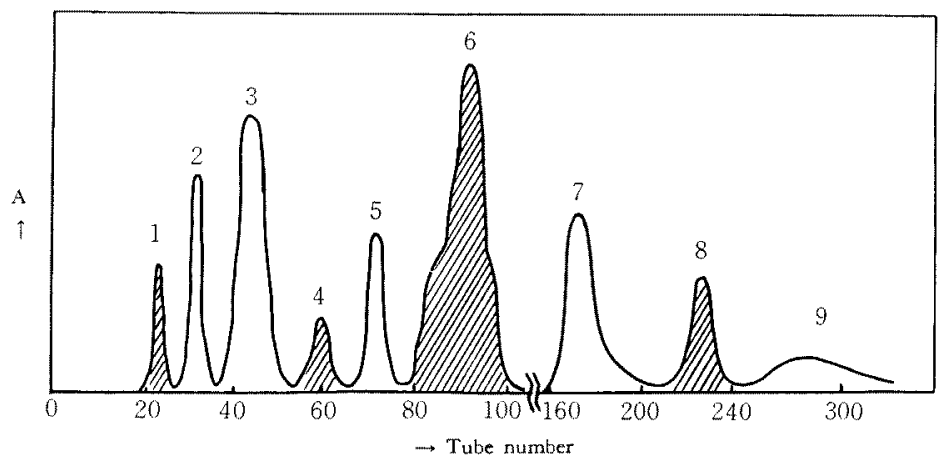

FIG. 1. Fractionation of Sample by Cellulose Column.

$2 \times 50 \mathrm{~cm}$ column

Every $2 \mathrm{ml}$ was collected.

Solvent; $n-\mathrm{BuOH}$ sat, with $1.5 \mathrm{~N}$ aq. $\mathrm{NH}_{4} \mathrm{OH}$

Visualized by diazo reaction ( Red, $O$ Yellow).

14) S. Moore, and W.H. Stein, J. Biol. Chem,, 211,893 (1954). 


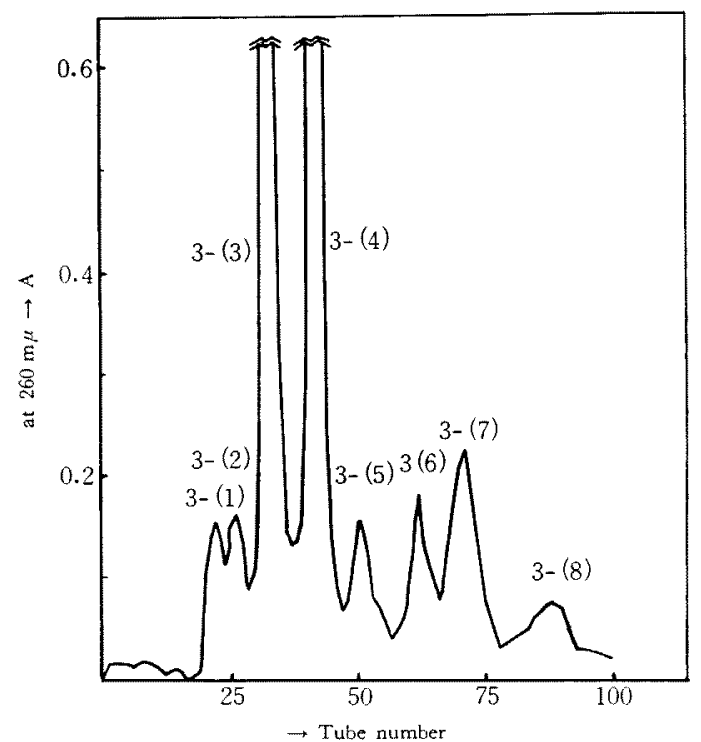

FIG. 2. Rechromatography of Fraction 3. Amberlite XE-64, $100 \sim 200$ mesh $\mathrm{H}^{+}$form $0.65 \times 95 \mathrm{~cm}$. Solvent ; Me-CO-Et : Me-CO-Me : $0.2 \mathrm{~N} \mathrm{HCl}=2: 1: 6$.

The crystal obtained was pressed on a clay plate, and then recrystallized from water. Finally about $15 \mathrm{mg}$ of colorless needle-shaped crystal (m.p. ${ }^{*} 124.5 \sim 12.5^{\circ} \mathrm{C}$ ) was obtained. Probably the crystal contained water of crystallization, since became opaque at 100 $105^{\circ} \mathrm{C}$. This material gave a yellow color with $1 \%$ phenol- $5 \%$ ferric chloride solution (Uffelman's test), and showed acid reaction with bromophenol blue or bromocresol green, and did not react with an aqueous bromine solution. In the molten state, the crystal smelled like of cinnamic acid. The ultraviolet spectrum is shown in Fig. 3 and the infra-red spectrum also shown in Fig. 4 (curve 3 ) .

Those facts showed that the compound was $\beta$-phenyllactic acid. The final confirmation was carried out by using the mixed melting point method with synthetic L- $\beta$-phenyllactic acid $\left(124 \sim 125^{\circ} \mathrm{C}\right)$ or $\mathrm{D}-\beta$-phenyllactic acid

* All melting poilnts were measured by a micro melting point measuring apparatus.

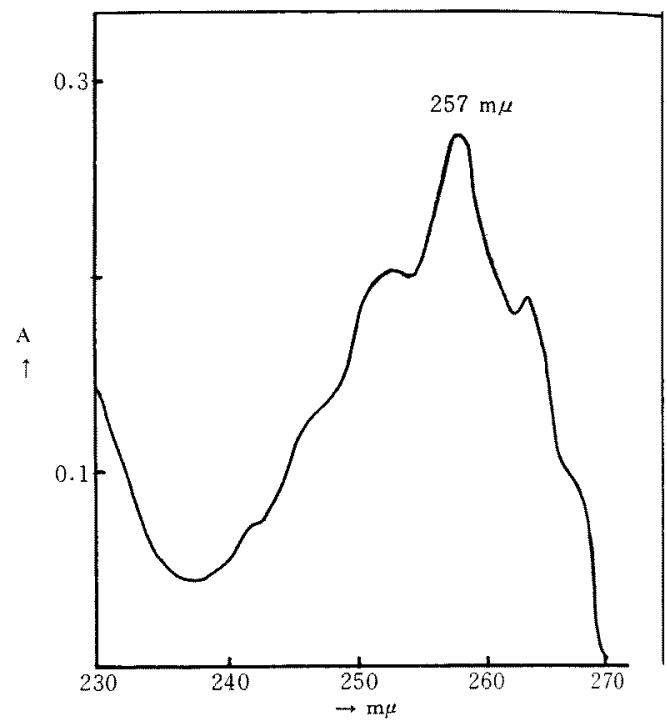

FIG. 3. UV-Spectrum of Fraction 3-(4).

$\left(124 \sim 125^{\circ} \mathrm{C}\right)$.

Both isomers were synthetized from $\mathrm{D}$-, and L-phenylalanine by means of nitrous acid. The IR-spectra are shown in Fig. 4 (curves 1, 2). Differences between the $\mathrm{D}$-form and $\mathrm{L}$ form in IR-spectra seems to consist in absorp. tion bands at $1000 \mathrm{~cm}^{-1}, 1035 \mathrm{~cm}^{-1}$, and at $880 \mathrm{~cm}^{-1}, 910 \mathrm{~cm}^{-1}$. The mixed melting point of $\mathrm{D}-\beta$-phenyllactic acid and the material under investigation was $98^{\circ} \mathrm{C}$. On the other hand, that of $\mathrm{L}-\beta$-phenyllactic acid and of the material was $124.5 \sim 125.5^{\circ} \mathrm{C}$ and no depres. sion was observed when the mixture was melted. Therefore, fraction 4- (4) was identified as $\mathrm{L}$ - $\beta$-phenyllactic acid. The IR-spectrum of this fraction was also the same as that of $\mathrm{L}-\beta$-phenyllactic acid. The odor was removed by repeated recrystallization, but cinnamic acid-like odor returned when allowed to stand for a long time at room temperature in a closed container or when heated in aqueous solution. Hence the acid presumably plays an important part in the aroma of rice

15) W. Grassmann, K. Hanning and M. Plöckl, Zeits. Physiol, Chem., 299, 258 (1955). 


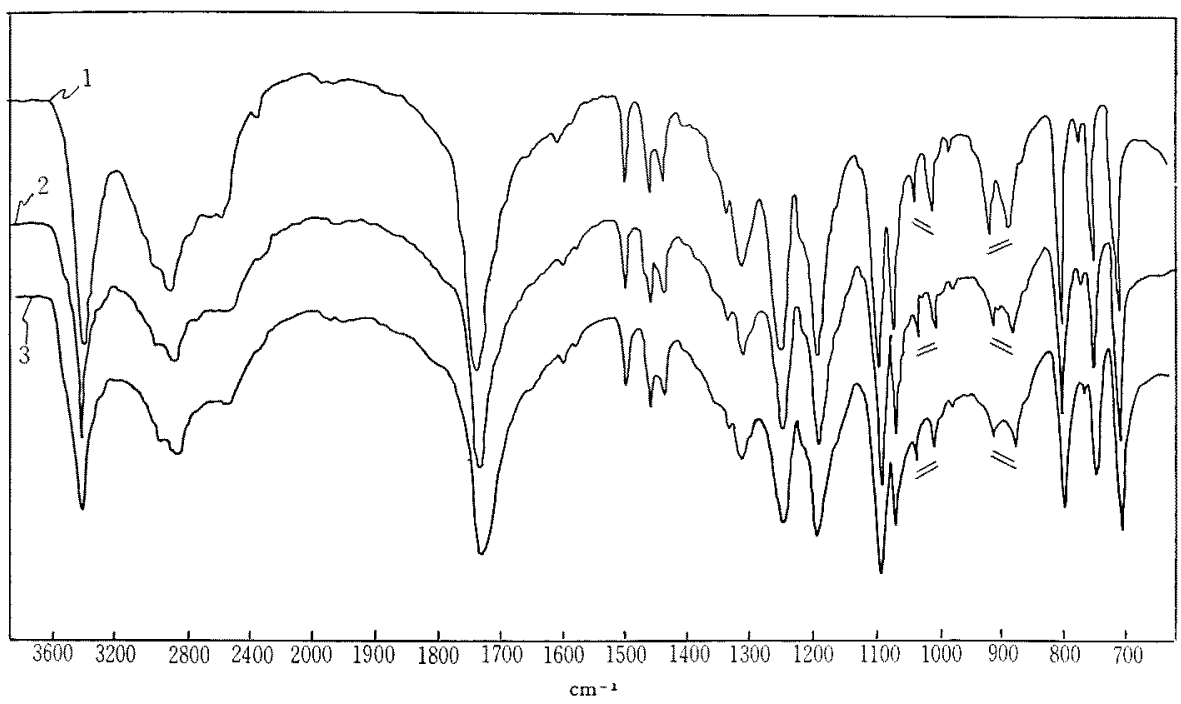

FIG. 4. IR Spectra of $\beta$-Phenyllactic Acid.

1) D-form, 2) L-form, 3) Isolated material.

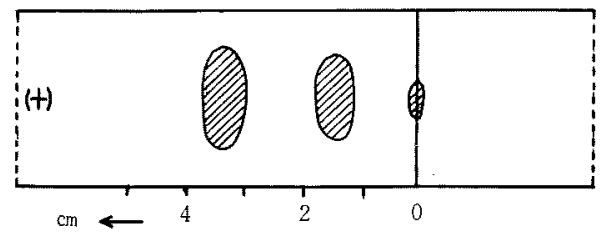

FIG. 5. Paper Ionogram of Fraction 6. pH. $3.9,600 \mathrm{~V}, 2 \mathrm{hrs}$.

Visualized with diazo rcaction.

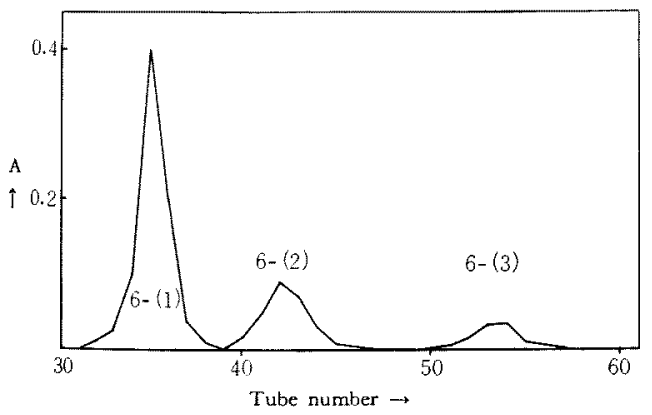

FIG. 6. Rechromatogram of Fraction 6.

vinegar.

Fractions 3-(6) and 3-(7) also had a pleasant aroma, but further studies were difficult because of very small quantities available.
(3) Separation, Fractionation and Identification of Fraction 6 (Fig. 1).

By evaporating the solvent of fraction 6 on a water bath, a brown oily substance was obtained, which formed brown needle-shaped crystals when left at room temperature. The crystals were applied to the paper ionophoresis as follows: electrolyte; $\mathrm{pH} 3.9$, acetic acidpyridine buffer ${ }^{15}$ ), 600 volts, 2 hours. The result is shown in Fig. 5. The ionogram was visualized by means of Pauly's diazo reaction. As shown in the Fig. 5, the crystalline mixture was separated into three substances. Consequently, fraction 6 was reapplied to an ion exchange column $(0.65 \times 80 \mathrm{~cm})$, and $1 \mathrm{ml}$ fractions were collected and tested for the presence of phenolic acids. The elution curve is shown in Fig. 6.

(3-1) Identification of fraction 6- (1), (peak 1 in Fig. 6) .

After the fraction was evaporated in a sulfuric acid desiccator under reduced pressure, slightly brown needle-shaped crystals (about $300 \mathrm{mg}$ ) were obtained. The crude crystals 
were recrystallized from ethyl acetate, producing colorless long needles which became opaque at $100 \sim 105^{\circ} \mathrm{C}$ and melted at 171.5 $172^{\circ} \mathrm{C}$. The crystals showed the following color reactions: blue with ferric sulfate-potassium ferricyanide, blue with phosphomolybdic acid-ammonia, reddish purple with Pauly's diazo reaction, purple with diazotized $p$-nitroaniline-sodium carbonate, and yellow with
Uffelman's test. Considering the infra-red spectrum, cf. Fig. 7, this compound was very probably $p$-hydroxyphenyllactic acid.

$L-p$-Hydroxy- $\beta$-phenyllactic acid was pre. pared by treating $\mathrm{L}$-tyrosine with sodium nitrite and hydrochloric acid. This acid melted at $171.5 \sim 172.5^{\circ} \mathrm{C}$, and the color reactions and other properties were all identical with the material separated from vinegar. The mixed

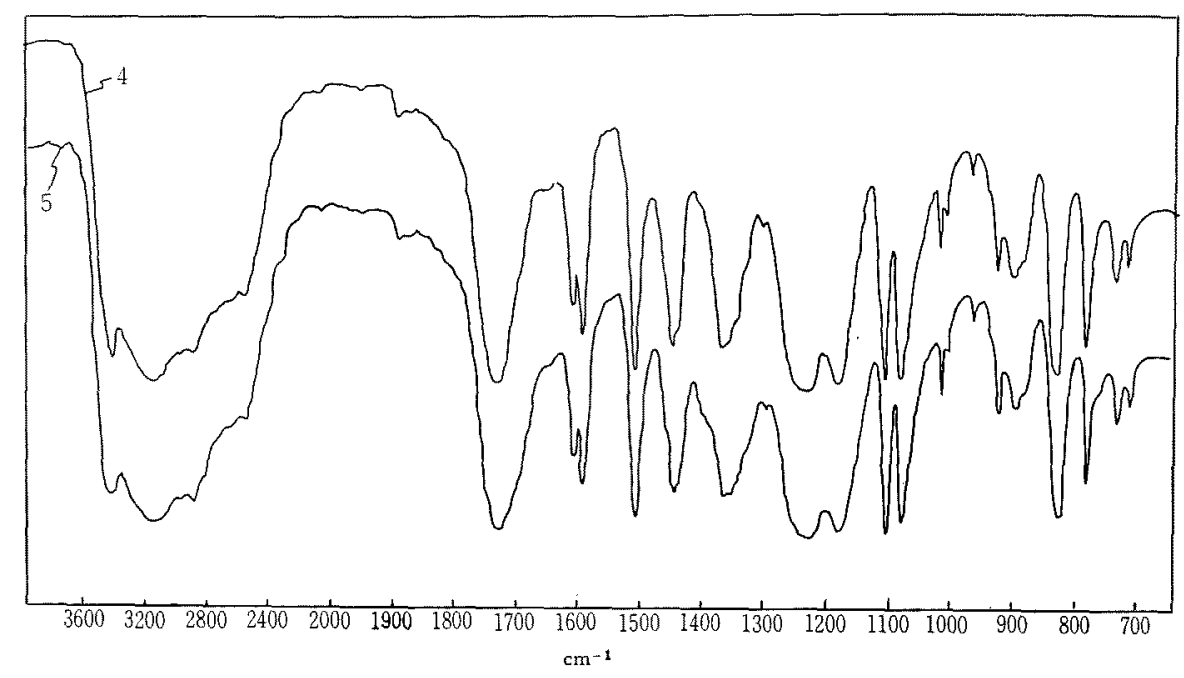

FIG. 7. IR Spectra of $L-p-H y d r o x y-\beta$-phenyllactic Acid.

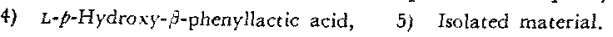

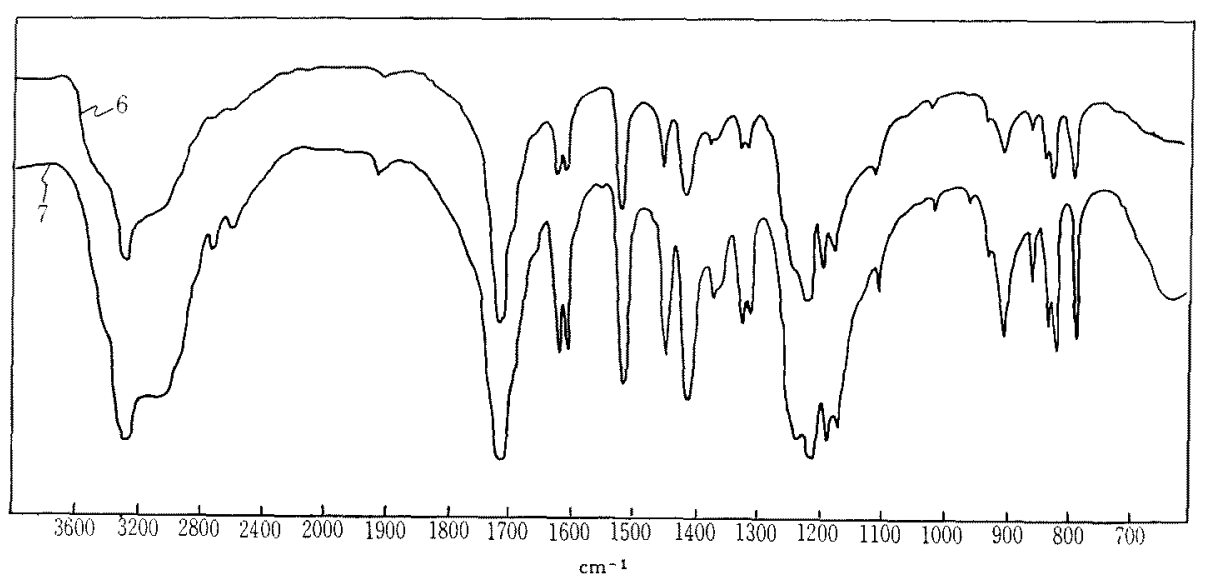

FIG. 8. IR Spectra of $p$-Hydroxyphenylacetic Acid.

6) p-Hydroxyphenylacetic acid, 7) isolated material 


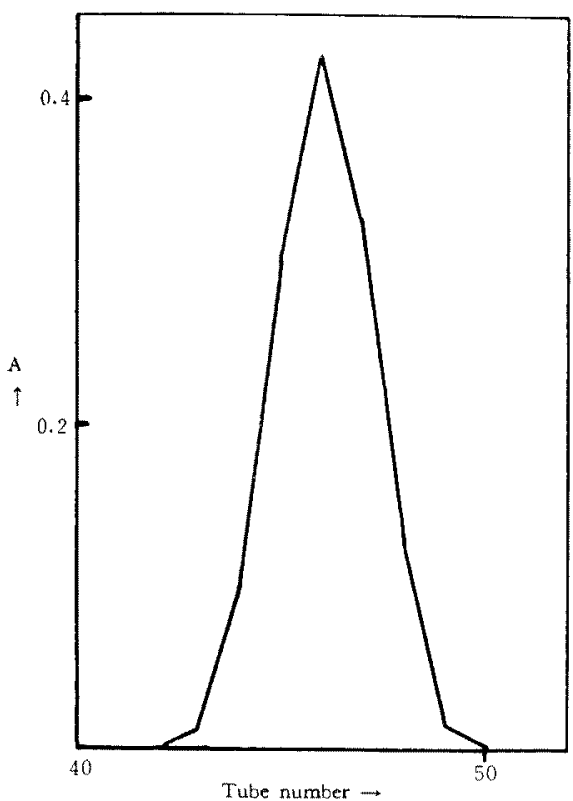

FIG. 9. Rechromatogram of Fraction 7. acid.

(3-2) Identification of fraction 6- (2), (peak 2 in Fig. 6).

The eluates of the column were evaporated in a sulfuric acid desiccator under reduced pressure. The residual material was rechromatographed and about $7 \mathrm{mg}$ of colorless plate-like crystals were obtained. Melting point was $149 \sim 150^{\circ} \mathrm{C}$. The crystalline product showed the following color reactions, red in Pauly's diazo reaction, purple with diazotized $p$-nitroaniline-sodium carbonate, and negative in ferric chloride and Uffelman's test. The infra-red spectrum shown in Fig. 8 and other physical properties, inferred that the crystalline substance was p-hydroxyphenylacetic acid. The IR-spectrum for authentic sample was exactly the same and the result of the mixed melting test was $149 \sim 150^{\circ} \mathrm{C}$. The fraction 6-(2) was then identified as p-hydroxy-

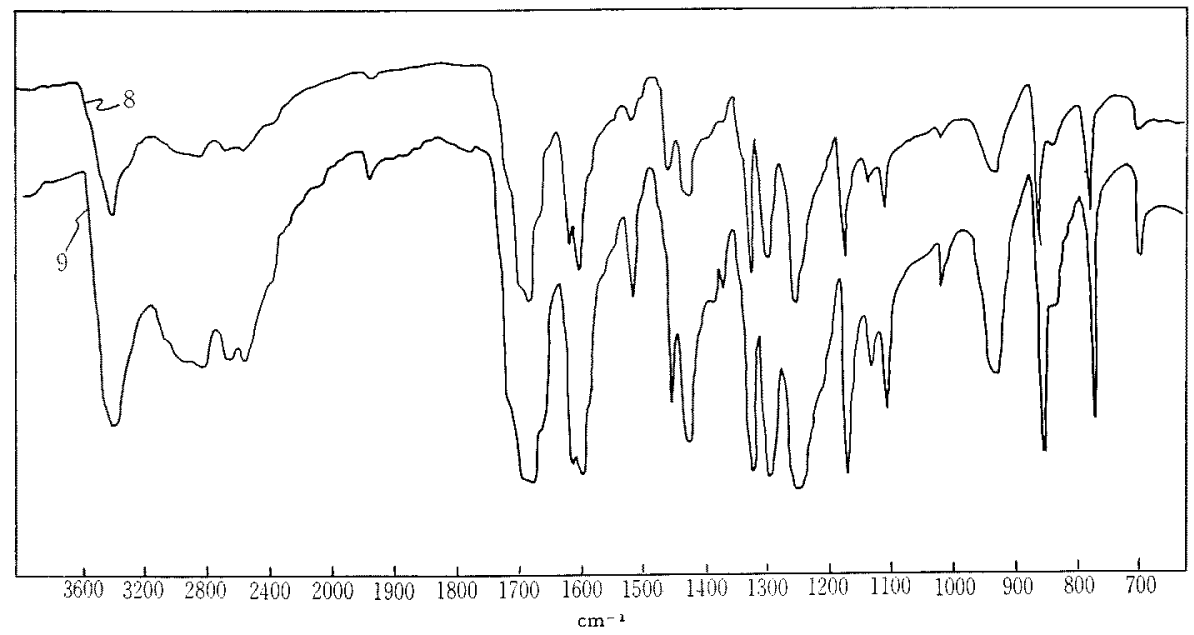

FIG. 10. IR Spectra of $p$-Hydroxybenzoic Acid.

8) p-Hydroxybenzoic acid, 9) Isolated material.

melting point was undepressed, $171.5 \sim 172^{\circ} \mathrm{C}$. phenylacetic acid.

The infra-red spectrum of an authentic material was also the same as that of the sample from vinegar. The material of fraction 6-(1) was identified as $\mathrm{L}$ - $p$-hydroxy- $\beta$-phenyllactic
(4) Segaration and Identification of Fraction 7, (peak 7 in Fig. 1).

The fraction 7 of the eluates from the cellulose column afforded a slightly brown oily 
material after evaporation of the solvent on a water bath. However, the material crystallized on standing. The crystals were purified further with column (b), and the elution curve obtained is shown in Fig. 9. Although the crystals obtained by recrystallization from water melted above $195^{\circ} \mathrm{C}$, the material seemed to be still impure. The crystals were sublimed in a sealed tube under reduced pressure and about $10 \mathrm{mg}$ of spindly crystals which melted at $215.5 \sim 216^{\circ} \mathrm{C}$ were obtained. This material showed the following color reactions: yellow in Pauly's diazo reaction, blue with ferric sulfate-potassium ferricyanide, and pink with diazotized $p$-nitroaniline. The IR spectrum is shown in Fig. 10 and the crystals were thought to be $p$-hydroxybenzoic acid. The spectrum of the fraction was the same as that of authentic p-hydroxybenzoic acid. Moreover, the mixed melting point was undepressed, $215.5 \sim 216^{\circ} \mathrm{C}$. Consequently, the material of fraction 7 was identified as $p$ hydroxybenzoic acid.

\section{DISCUSSION}

$p$-Hydroxy- $\beta$-phenyllactic acid has been reported to be formed besides tyrosol by the degradative action of Bact. lactis aerogenes on tyrosine ${ }^{7}$, and tyrosine was also proven to be degraded through $p$-hydroxyphenyllactic acid into $p$-hydroxyphenylacetic acid, and finally into $p$-cresol by the action of some kind colitis germs ${ }^{5}$.

$p$-Hydroxyphenylacetic acid has been identified as a metabolite of Hypochnus sasakii shiraii ${ }^{2)}$ and it has been reported that $p$-hydroxyphenylacetic acid was also formed from tyrosine by the action of Trichophyton gypseum ${ }^{6)}$. On the other hand, some bacteria which produce $p$-hydroxyphenylacetate by the oxidation of phenylacetic acid have been re. ported ${ }^{11)}$.

$\beta$-Phenyllactic acid seems to originate from phenylalanine, but no papers on the subject have been found.

It has been reported that small quantities of $p$-hydroxybenzoic acid are contained in cheese $^{3)}$, and that some plants, e.g. an Indian bean $^{12)}$, and a broad bean ${ }^{13}$, contain a considerable amount of $p$-hydroxybenzoic acid.

There are many reports on the existence of tyrosol in sake1), matured "moromi" (unrefined sake or soy) and cider"10) or autolyzed yeast ${ }^{\text {s). }}$

The fractions obtained from the ethersoluble fraction of rice vinegar and soluble in aqueous sodium bicarbonate were separated by cellulose columns and Amberlite XE-64 ion exchange resin column and shown to consist of at least 18 compounds. Among them the following five compounds were identified: $\quad p$-hydroxyphenylethylalcohol, $p$-hydroxyphenylacetic acid, $p$-hydroxy- $\beta$-phenyllactic acid, phenyllactic acid, and $p$-hydroxybenzoic acid.

Acknowledgement. The authors are indebted to Mr. M. Kotegawa of Fundokin Soy Sauce Manufacturing Co. for providing facilities for this work. 